\title{
Terrestrial ecosystem carbon dynamics and climate feedbacks
}

\author{
Martin Heimann \& Markus Reichstein
}

\section{Recent evidence suggests that, on a global scale, terrestrial ecosystems will provide a positive feedback in a warming world, albeit of uncertain magnitude.}

It has only been recognized relatively recently that biological processes can control and steer the Earth system in a globally significant way. Terrestrial ecosystems constitute a major player in this respect: they can release or absorb globally relevant greenhouse gases such as carbon dioxide $\left(\mathrm{CO}_{2}\right)$, methane and nitrous oxide, they emit aerosols and aerosol precursors, and they control exchanges of energy, water and momentum between the atmosphere and the land surface. Ecosystems themselves are subject to local climatic conditions, implying a multitude of climate-ecosystem feedbacks that might amplify or dampen regional and global climate change. Of these feedbacks, that between the carbon cycle and climate has recently received much attention. Large quantities of carbon are stored in living vegetation and soil organic matter, and liberation of this carbon into the atmosphere as $\mathrm{CO}_{2}$ or methane would have a serious impact on global climate. By definition, the carbon balance of an ecosystem at any point in time is the difference between its carbon gains and losses. Terrestrial ecosystems gain carbon through photosynthesis and lose it primarily as $\mathrm{CO}_{2}$ through respiration in autotrophs (plants and photosynthetic bacteria) and heterotrophs (fungi, animals and some bacteria), although losses of carbon as volatile organic compounds, methane or dissolved carbon (that is, non$\mathrm{CO}_{2}$ losses) could also be significant. Quantifying and predicting these carbon-cycle-climate feedbacks is difficult, however, because of the limited understanding of the processes by which carbon and associated nutrients are transformed or recycled within ecosystems, in particular within soils, and exchanged with the overlying atmosphere.

There is ample empirical evidence that the terrestrial component of the carbon cycle is responding to climate variations and trends on a global scale. This is exemplified by the strong interannual variations in the globally averaged growth rate of atmospheric $\mathrm{CO}_{2}$, which is tightly correlated with El Niño-Southern Oscillation climate variations (Fig. 1). Many lines of evidence show that the variations in the $\mathrm{CO}_{2}$ growth rate are mainly caused by terrestrial effects, in particular the impacts of heat and drought on the vegetation of western Amazonia and southeastern Asia, leading to ecosystem carbon losses through decreased vegetation productivity and/or increased respiration. These interannual variations reflect short-term responses of the carbon cycle to climate perturbations, however, and cannot be expected to hold over longer timescales. Conversely, the close correlation between atmospheric concentrations of $\mathrm{CO}_{2}$, methane and nitrous oxide and global climate during the last glacial cycles ${ }^{1}$ indicates that ecosystem-climate interactions are also operating on timescales of millennia and longer.

Unfortunately, empirical evidence for global carbon-cycle-climate interactions on the timescale pertinent to current global climate change, that is, decades to centuries, is much scarcer. Hence the assessment on these timescales has to be attempted by means of comprehensive, coupled carbon-cycle-climate models. A recent comparison of different model simulations for the industrial epoch (the past $\sim 150$ years) and the next 100 years, made on the basis of a standard model of $\mathrm{CO}_{2}$ emissions, has shown a variety of responses ${ }^{2}$. Almost all the models show terrestrial $\mathrm{CO}_{2}$ sequestration in the early phase of industrial expansion in the nineteenth and twentieth centuries but a substantial decrease in sequestration as the world warms (Fig. 2) (see page 297). In some models, the terrestrial carbon cycle even becomes a substantial source of atmospheric $\mathrm{CO}_{2}$ and thus strongly amplifies global climate change. The rather wide spread of results from the different model simulations demonstrates on the one hand genuine differences in the simulated climate change, and on the other hand the very poor understanding of processes in functioning ecosystems as represented in these models.

\section{Changing concepts of ecosystem carbon dynamics}

In carbon-cycle-climate models, the effect of the prevailing climate on the carbon balance in terrestrial ecosystems is described mostly by relatively simple response functions and kinetic concepts of $\mathrm{CO}_{2}$ uptake by photosynthesis and loss by respiration. The fundamental paradigm adopted by researchers over the past two decades has been that photosynthetic uptake is stimulated both by increasing $\mathrm{CO}_{2}$ and, in boreal and temperate regions, by rising temperature, although both effects are expected to saturate at high levels of these variables. On the other hand, the biological processes underlying respiration are assumed to respond to temperature in an exponential way but are not affected by the $\mathrm{CO}_{2}$ concentration ${ }^{3,4}$. This leads to the conclusion that the biosphere is able to provide negative feedback to rising $\mathrm{CO}_{2}$ and temperature until the temperature climbs so high that the stimulating

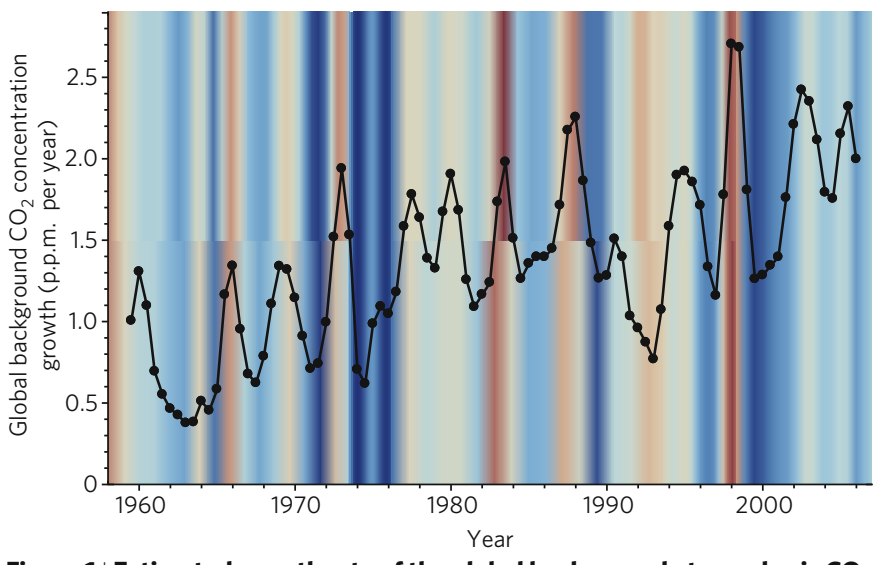

Figure 1 Estimated growth rate of the global background atmospheric $\mathrm{CO}_{2}$ concentration. Global $\mathrm{CO}_{2}$ concentration is estimated from measurements from the South Pole and the Mauna Loa (Hawaii) long-term monitoring stations (ref. 17, updated). The black dots represent centred annual averages calculated at six-monthly intervals. The coloured background shows the variation of the multivariate El Niño-Southern Oscillation index. Blue shades indicate negative phases, and brown shades positive phases, of this index ${ }^{18}$. p.p.m., parts per million. 


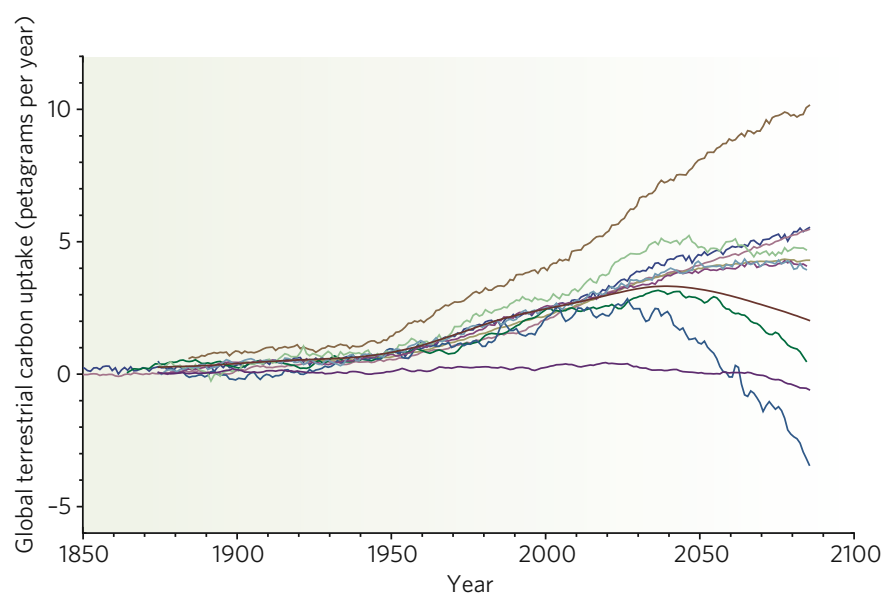

Figure 2 Comparison of estimated global terrestrial carbon uptake in different models of the carbon-cycle-climate system. Global terrestrial carbon uptake was simulated by 11 coupled carbon-cycle-climate models driven with carbon emissions from the SRES-A2 emissions profile. Data are taken from the Coupled Carbon Cycle Climate Model Intercomparison Project ${ }^{2}$, with uptake rates smoothed with a 30 -year moving average.

effect on respiration exceeds the $\mathrm{CO}_{2}$ fertilization effect. This fundamental principle reflects the behaviour of almost all the models in the comparative study described earlier ${ }^{2}$.

The fundamental simplifying assumption behind this reasoning is that above-ground assimilatory processes (plant photosynthesis) and below-ground heterotrophic respiratory processes (for example, decomposition by fungi and respiration by animal and bacterial life in the soil) can be conceptually isolated and analysed separately. Although this conceptual model has provided valuable guidance for experimental and model design, evidence has accumulated in recent years that above- and below-ground processes are intimately linked, constituting a complex and dynamic system with non-negligible interactions. Hence, the situation is much more complicated than previously thought and might result in unexpected dynamics through interactions between physical, chemical and biological processes within the ecosystem - particularly in the soil. This implies that, beyond rising $\mathrm{CO}_{2}$ levels and rising temperature, other climatic and environmental factors might modify, or even dominate, the carbon balance of the world's ecosystems. Furthermore, not only the long-term rate of change of mean values of parameters such as temperature but also alterations in their variability, including greater extremes, may be crucial to ecosystem carbon dynamics.

\section{Ecosystems in a multi-factor world}

Primary productivity in more than half of the world's ecosystems is substantially limited by the availability of water. Hence, changes in precipitation will have direct effects on ecosystem carbon dynamics. In a warmer world, evaporation is expected to increase, leading to a more negative water balance, whereas decreased water loss through stomata in a $\mathrm{CO}_{2}$-richer world will tend to mitigate this effect. The net effect (production minus respiration) of a more negative overall water balance probably depends on the water-holding capacity of the soil, the vertical distribution of carbon and roots in the soil, and the general drought sensitivity of the vegetation. For instance, if most of the soil carbon is concentrated at the top of the soil, while roots go deep into a soil with high water-holding capacity, or even tap the groundwater, soil carbon decomposition will initially be more strongly affected by drought than will vegetation productivity, as the topsoil dries out first. Water limitation may even suppress the effective ecosystem-level response of temperature on respiration ${ }^{5}$. Conversely, if soil water-holding capacity is low, as in shallow soils, vegetation productivity will be strongly affected by a negative water balance. Hence, under drier conditions, there are predictions of increased sequestration by suppression of respiration and of net loss of carbon through decreased productivity ${ }^{6,7}$.
A second important interacting factor is the available nitrogen, which often determines the magnitude of the $\mathrm{CO}_{2}$ fertilization effect and may suppress it completely if nitrogen is limiting ${ }^{8,9}$ (see page 293). There are also indications of strong interactions between water and nitrogen, with nitrogen becoming more limiting under drier conditions. Other factors to be considered are changes in the amount and quality (direct or diffuse) of light, which can alter vegetation productivity ${ }^{10}$, and increases in air pollutants and ozone, with their detrimental effects on primary production $^{11}$.

\section{Climate variability and extremes}

The terrestrial biosphere does not respond to a mean climate but to the concrete time series of actual weather conditions. Consequently, anticipated reactions to gradual mean changes in climate components and atmospheric concentrations of trace gases might be misleading if variability and extremes are not considered. A recent wake-up call in this respect was the European heatwave in the summer of 2003, when the cumulative European carbon sequestration of five years was undone within a few months through the reaction of the terrestrial biosphere to these extreme hydrological and climatic conditions ${ }^{6}$. Lag effects - for example, increased tree death in the years after an extreme event - may yet increase the effect of the heatwave on European ecosystems. Apart from extremes, changes in the seasonal distribution of climate factors may be decisive. This is particularly evident for water-carbon-cycle interactions, where changes in the frequency or timing of rainfall without changes in the annual total may have profound effects on ecosystem productivity $^{12}$, as these factors determine whether the water will be used by plants and transpired, or will just run off or evaporate.

Similarly, temporal changes in constellations of water deficit, wind speed, air temperature and humidity modify the frequency and severity of forest fires and the consequent rapid loss of carbon from the biosphere. Wind-throws due to a single large storm kill trees and so make previously 'locked-in carbon' subject to decay and release of $\mathrm{CO}_{2}$. Changes in the seasonality of temperature can also have consequences; for example, the warmer winter and spring in large parts of the Northern Hemisphere in 2006/2007 induced earlier leafing and flowering, leading to greater vulnerability of plants to late frosts. Our predictive ability in respect of such local weather conditions is clearly limited by both the level of detail that can be incorporated into atmosphere-ocean general circulation models and our understanding of the seasonal dynamics of ecosystems and their ability to acclimate on a variety of timescales.

\section{Nonlinear ecosystem feedback loops}

As discussed above, the net effect of any environmental change on the carbon balance in an ecosystem depends on the reactions of both photosynthesis and respiration; in other words, on above-ground and below-ground processes. Below-ground processes in particular are still poorly understood yet provide a number of potentially important feedbacks in the carbon-cycle-climate system. Here, we focus on below-ground processes and recent important findings on biological-physicochemical interactions that are not considered in current simulations of the carbon-cycle-climate system; Figure 3 illustrates three exemplary and simplified conceptual descriptions of subsystems by means of cause-and-effect pathways that are related to the dynamics of ecosystem carbon.

Figure 3a shows potential interactions between microbial metabolism and the physics of permafrost thawing and carbon release. Current estimates of carbon stored deep-frozen in permafrost regions amount to at least 400 petagrams $\left(4 \times 10^{11}\right.$ tonnes) of carbon (ref. 13) that is relatively unprocessed and labile as the frozen state protects it from microbial decomposition. Moss and turf layers provide very good insulation against the atmosphere. With rising summer temperatures, these soils begin to melt, the carbon becomes metabolized and microbial metabolism may release enough heat (the 'dung-heap effect') to facilitate further melting, providing a nonlinear positive-feedback mechanism to enhance permafrost melting and, through methane and $\mathrm{CO}_{2}$ emissions, to increase the greenhouse effect. Model simulations indicate that a run-away dynamic 
may be triggered by a few warm years, but the strength of this feedback mechanism and the realism of these simulations remain unclear ${ }^{14}$.

Another mechanism for potential mobilization of large amounts of carbon is the so-called 'microbial priming effect'. It has been shown in several experimental systems that the addition of substrates with readily available energy (for example, glucose and cellulose) to the soil stimulates the decomposition of 'old' soil carbon. Sébastien Fontaine et al. ${ }^{15,16}$ showed that simply by adding cellulose to the soil they could mobilize carbon from the subsoil of grasslands that was assumed to be stable, whereas other factors such as temperature, nitrogen addition or increasing oxygen concentration had no effect. Counterintuitively, addition of such material even induced a net loss of carbon from the soil samples, as the soil carbon stock is large. In the context of climate change this effect may induce a positivefeedback effect, particularly in grassland soils (Fig. 3b). Increasing $\mathrm{CO}_{2}$ concentrations can lead to enhanced below-ground allocation of labile carbon through roots and root exudates, which can enhance microbial activity and foster decomposition of carbon material that has been deemed stable but was in fact not being attacked because microbes were not active. Also, if rooting patterns change, either because of altered precipitation or as part of general vegetation dynamics, carbon input into deeper layers that were not rooted before might induce release of old carbon through this mechanism.

Last but not least, the interaction of the carbon and nitrogen cycles offers a plethora of mechanisms that could alter expected ecosystem carbon responses to the prevailing trend in climate change. Some of these are shown in Fig. 3c. In nitrogen-limited ecosystems, nitrogen nutrition limiting the $\mathrm{CO}_{2}$ fertilization effect on canopy assimilation is regularly found after a few years of increasing $\mathrm{CO}_{2}$ levels ${ }^{9}$. There are also indications that nitrogen availability influences the decomposition of soil organic matter. Fungi use lignin, an abundant, stable organic substance found in plant cell walls, as a nitrogen source under conditions of limited nitrogen availability. Enhanced decomposition of lignin may lead to a positive feedback in response to rising atmospheric $\mathrm{CO}_{2}$. On timescales longer than a few years, however, acclimation or change in species composition, or, for example, increased nitrogen fixation through increased carbohydrate input into the soil, may relax or even overcompensate for the nitrogen-limitation effects. Also, an interaction with microbial 'priming' (see above) through more intensive and deeper plant rooting is not unlikely, as a decrease in nitrogen availability often leads to a larger allocation of carbon to roots.

Thus, the picture of a gradual increase in $\mathrm{CO}_{2}$ and temperature, with separable, non-interactive effects on assimilation and respiration, needs to be replaced by a multifactor view, by more sophisticated characterization of changes in environmental factors, including their variability and extremes, and, maybe most importantly, by stronger integrative consideration of complex interactions between ecosystem processes at different levels of organization. Most of these emerging characteristics point to a lower $\mathrm{CO}_{2}$-sequestration potential than estimated by current models and highlight the vulnerability of soil carbon that has accumulated over millennia. A positive feedback of ecosystem carbon to climate change might occur earlier and more strongly than currently predicted in coupled carbon-cycle-climate models ${ }^{2}$.

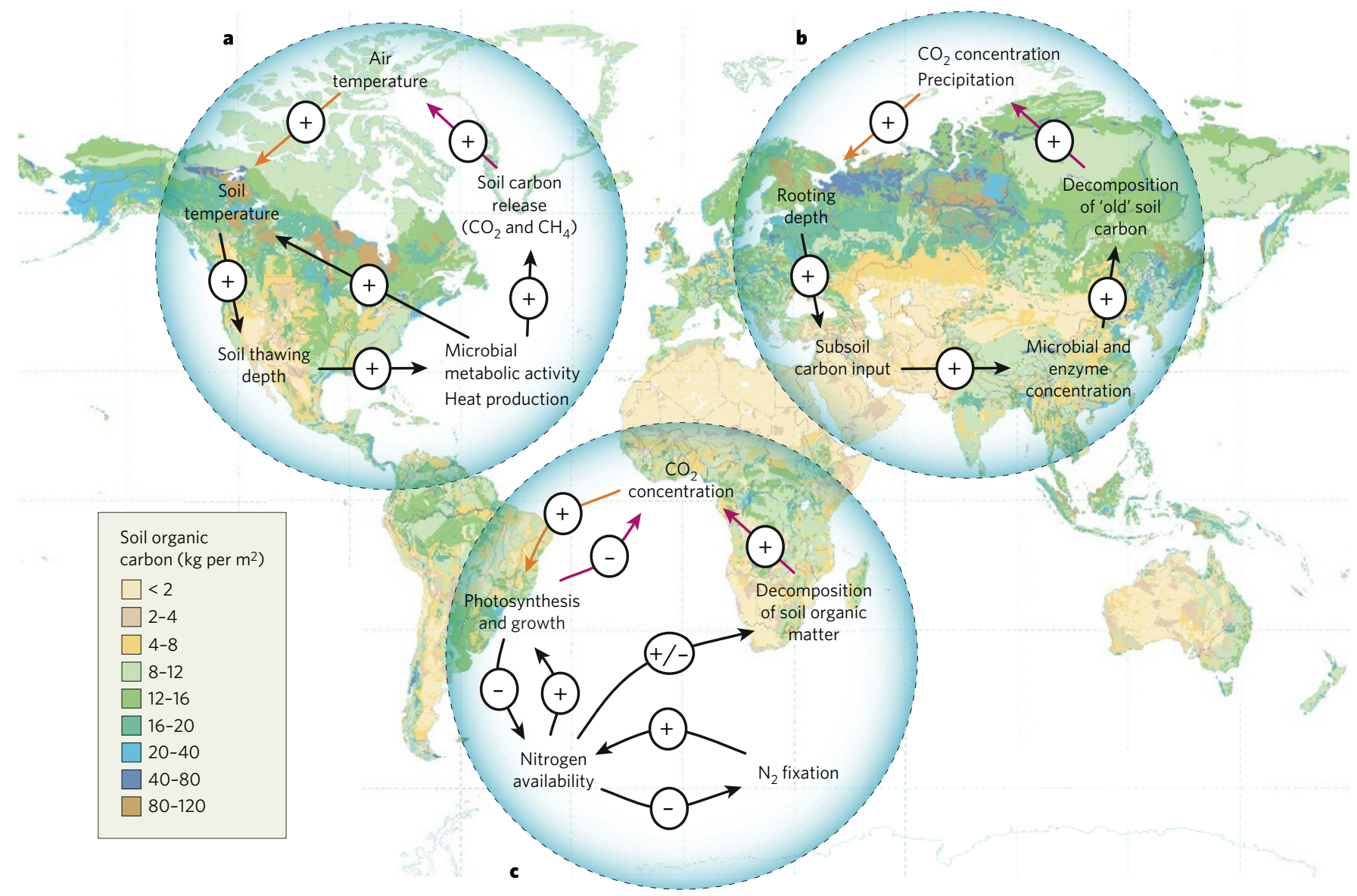

Figure 3 | Feedback loops that could be induced by climate change in belowground ecosystem carbon balances. The three examples given here are crucial processes in the ecosystem, shown in simplified form. a, Potential interactions between microbial metabolism and the physics of permafrost thawing and carbon release. $b$, The 'microbial priming effect'. An increase in carbon and energy sources easily utilized by microbes can stimulate the decomposition of 'old' soil carbon, especially in grassland soils. In the context of climate change this effect may have a positive-feedback effect on $\mathrm{CO}_{2}$ increase and global warming. c, Interactions between the carbon and nitrogen cycles shown here could alter expected ecosystem carbon responses to the prevailing trend of climate change. Pink arrows denote effects of terrestrial ecosystems on climate, orange arrows denote effects of climate change on terrestrial ecosystems, and black arrows denote interactions within ecosystems. The background image is a world map of soil organic carbon. (Map reproduced, with permission, from

USDA-NRCS, http://soils.usda.gov/use/worldsoils/mapindex/soc.html.) 


\section{Future directions}

It is evident that large uncertainties remain in our ability to assess terrestrial carbon-cycle-climate feedbacks over the coming decades. Current experiments give ambiguous results and do not provide definite conclusions on the importance of the mechanisms discussed above. Overall, it is likely that, at least on a global scale, terrestrial ecosystems will provide a positive, amplifying feedback in a warming world, albeit of uncertain magnitude. An important improvement in our understanding might be obtained by the combination of longterm multifactorial experiments with non-destructive ecosystem-level observations, such as whole-ecosystem flux measurements, and the integration of the results with ecosystem modelling in a multiple-constraint framework. As long as there is no fundamental understanding of the processes involved, simulations of coupled carbon-cycle-climate models can only illustrate the importance of, but do not show, a conclusive picture of the multitude of possible carbon-cycle-climate system feedbacks. Moreover, strong interactions between the natural processes described here and anthropogenic changes in land use, cover and management have to be expected.

Martin Heimann and Markus Reichstein are the Max Planck Institute for Biogeochemistry, Hans-Knöll-Strasse 10, D-07745 Jena, Germany.

1. Petit, J. R. et al. Climate and atmospheric history of the past 420,000 years from the Vostok ice core, Antarctica. Nature 399, 429-436 (1999).

2. Friedlingstein, P. et al. Climate-carbon cycle feedback analysis: results from the (CMIP)-M4 model intercomparison. J. Climate 19, 3337-3353 (2006).

3. Kirschbaum, M. U. F. The temperature dependence of organic-matter decomposition - still a topic of debate. Soil Biol. Biochem. 38, 2510-2518 (2006).

4. Davidson, E. A. \& Janssens, I. A. Temperature sensitivity of soil carbon decomposition and feedbacks to climate change. Nature 440, 165-173 (2006).
5. Reichstein, M. et al. Determinants of terrestrial ecosystem carbon balance inferred from European eddy covariance flux sites. Geophys. Res. Lett. 34, L01402, doi:10.1029/ 2006GL027880 (2007).

6. Ciais, P. et al. Europe-wide reduction in primary productivity caused by the heat and drought in 2003. Nature 437, 529-533 (2005).

7. Saleska, S. R. et al. Carbon in Amazon forests: unexpected seasonal fluxes and disturbanceinduced losses. Science 302, 1554-1557 (2003).

8. Hyvonen, R. et al. The likely impact of elevated $\left[\mathrm{CO}_{2}\right]$, nitrogen deposition, increased temperature and management on carbon sequestration in temperate and boreal forest ecosystems: a literature review. New Phytol. 173, 463-480 (2007).

9. Reich, P. B. et al. Nitrogen limitation constrains sustainability of ecosystem response to $\mathrm{CO}_{2}$. Nature 440, 922-925 (2006).

10. Farquhar, G. D. \& Roderick, M. L. Atmospheric science: Pinatubo, diffuse light, and the carbon cycle. Science 299, 1997-1998 (2003)

11. Sitch, S., Cox, P. M., Collins, W. J. \& Huntingford, C. Indirect radiative forcing of climate change through ozone effects on the land-carbon sink. Nature 448, 791-794 (2007).

12. Knapp, A. K. et al. Rainfall variability, carbon cycling, and plant species diversity in a mesic grassland. Science 298, 2202-2205 (2002).

13. Sabine, C. L. et al. in The Global Carbon Cycle: Integrating Humans, Climate and the Natural World (eds Field, C. \& Raupach, M.) 17-44 (Island, Washington DC, 2004).

14. Khvorostyanov, D. V., Krinner, G., Ciais, P., Heimann, M. \& Zimov, S. A. Vulnerability of permafrost carbon to global warming. Part 1. Model description and role of heat generated by organic matter decomposition. Tellus (in the press).

15. Fontaine, S., Bardoux, G., Abbadie, L. \& Mariotti, A. Carbon input to soil may decrease soil carbon content. Ecol. Lett. 7, 314-320 (2004)

16. Fontaine, S. et al. Stability of organic carbon in deep soil layers controlled by fresh carbon supply. Nature 450, 277-280 (2007)

17. Keeling, C. D. et al. Exchanges of Atmospheric $\mathrm{CO}_{2}$ and ${ }^{13} \mathrm{CO}_{2}$ with the Terrestrial Biosphere and Oceans from 1978 to 2000. I. Global aspects (Scripps Institution of Oceanography, San Diego, 2001).

18. Wolter, K. \& Timlin, M. S. Measuring the strength of ENSO events - how does 1997/98 rank? Weather 53, 315-324 (1998).

Author Information Reprints and permissions information is available at npg.nature.com/reprints. Correspondence should be addressed to M.H. (martin.heimann@bgc-jena.mpg.de). 